\title{
Chiari Malformation Presenting as Loss of Cerebellar Substance on Computed Tomography
}

\author{
Stephen S. Gebarski, M.D., and Harry S. Greenberg, M.D. \\ Division of Neuroradiology, Department of Radiology, and Department of Neurology, University of Michigan Medical \\ Center, Ann Arbor, Michigan
}

\begin{abstract}
Gebarski SS, Greenberg HS. Chiari malformation presenting as loss of cerebellar substance on computed tomography. Surg Neurol $1984 ; 21: 562-4$.

Cerebral computed tomography (CT) is the primary imaging modality in the investigation of suspected cerebellar degeneration. A case is presented in which an inaccurate clinical and radiologic diagnosis of olivopontocerebellar degeneration resulted from CT imaging demonstrating loss of cerebellar substance. Subsequent clinical recognition of downbeat nystagmus led to a diagnosis of Chiari malformation. This malformation was classified as a "severe" Chiari type I via clivomyelography and angiography. Surgical decompression resulted in marked clinical improvement. Visualization of the loss of cerebellar substance should not be considered to exclude Chiari malformation.
\end{abstract}

KEY WORDS: Chiari malformation; Computed tomography; Loss of cerebellar substance

Although the diagnosis of Chiari malformation via computed tomography (CT) is known to be difficult [4-6], the relationship between loss of cerebellar substance and this malformation has not been stressed. In fact, previous publications appear to suggest that visualizing loss of cerebellar substance provides evidence against the diagnosis of Chiari malformation [4-6]. A case is presented in which this inaccurate conclusion was made and the diagnosis of Chiari malformation delayed.

\section{Case Report}

A 40-year-old right-handed white woman was referred in May 1982 for evaluation of an 8-month history of instability of gait and visual blurring while reading. A

Address reprint requests to: Stephen S. Gebarski, M.D., Department of Radiology, Box 13, University of Michigan Hospitals, Ann Arbor, Michigan 48109. clinical and computed tomographic diagnosis of olivopontocerebellar degeneration was made. There was no history of abuse of alcohol or any other substance, toxic exposure, trauma, seizure, or a previous operation. Family history was normal. Initial neurological examination revealed first-degree horizontal and rotatory nystagmus on lateral gaze, dystaxia of all four limbs, and mild rightsided hemiparesis. Further testing showed subtle downbeat nystagmus and hypesthesia of the C- 4 dermatome to pinprick. A CT scan performed at another hospital 7 months before referral demonstrated moderate diffuse loss of superficial cerebellar substance. Brainstem volume was normal. Slight caudal displacement of the fourth ventricle was not initially appreciated (Figure 1). Downbeat nystagmus, however, a type of central vestibular nystagmus frequently found in lesions near the cervical-medullary junction $[1,2]$, prompted a search for a Chiari malformation. Iophendylate (Pantopaque) clivomyelography demonstrated herniation of the cerebellar tonsils to the level of $\mathrm{C}-2$ (Figure 2). Cerebral angiography demonstrated similar displacement of the tonsillohemispheric branches of the posterior inferior cerebellar arteries (Figures 3 and 4). Anatomically the pons, medulla oblongata, and fourth ventricle appeared to be displaced slightly caudally (Figures 1-4). There was no evidence of myelomeningocele or encephalomeningocele. Decompressive suboccipital craniectomy with complete laminectomy of C1-2 and dural grafting was performed in June 1982; subsequently, gait and vision gradually returned to normal. Neurological examination yielded totally normal results 2 months postoperatively.

\section{Discussion}

Three types of Chiari malformation are well known [1-8]. Type I shows only varying degrees of caudal displacement of the cerebellar tonsils and inferior cerebellum into the vertebral canal. Type II is similar to type $\mathbf{I}$, but shows a caudally displaced pons and medulla oblongata with an elongated fourth ventricle and, almost always, 


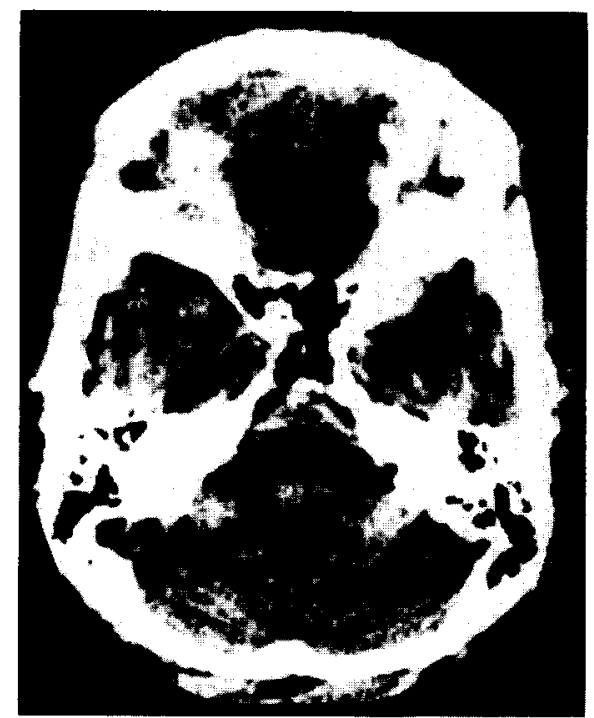

A

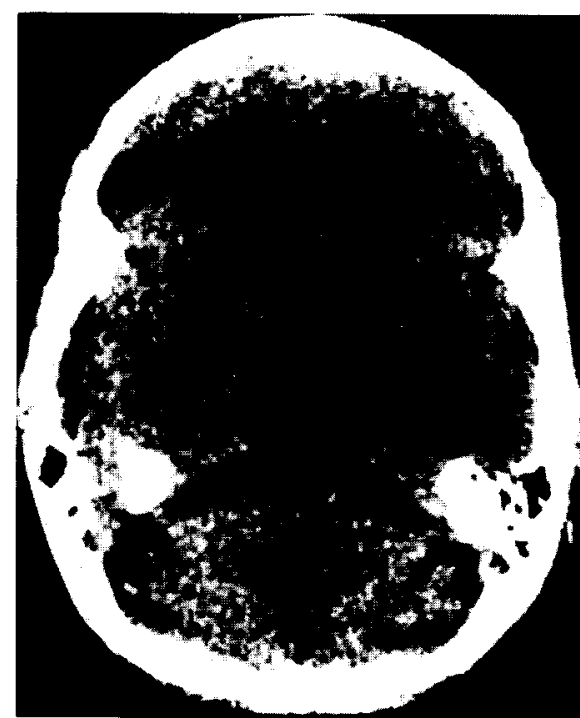

B

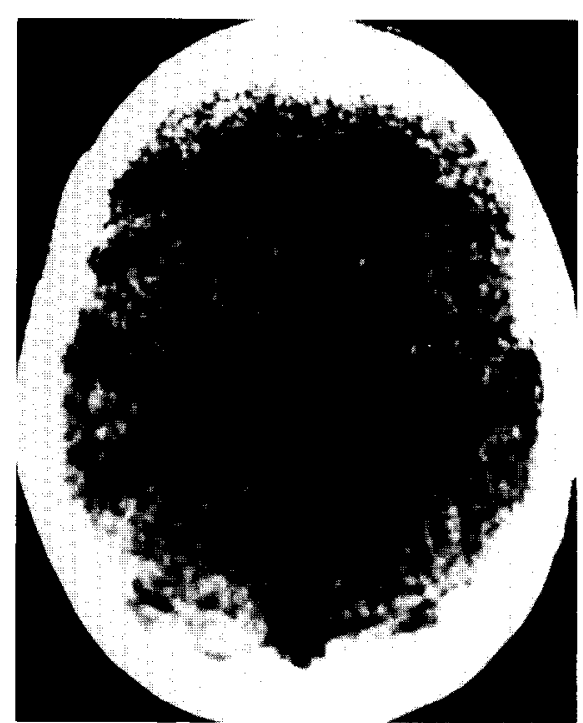

C

Figure 1. Computed tomography scans showing moderate loss of superficial cerebellar substance. All three sections reveal prominent subarachnoid spaces about the cerebellar folia, particularly in the superior vermis (C). Slight caudal displacement of the fourth ventricle, notoriously difficult to evaluate on axial computed tomography, was not initially detected. Volume of pons (A) and midbrain (B) is normal.

some type of meningocele. In type III, there is displacement of the medulla oblongata, fourth ventricle, and cerebellum into an occipitocervical encephalomeningocele [8]. The types thus described are useful for general purposes. The caudally displaced fourth ventricle, nearly normal pontine and medullary positions, and lack of some type of meningocele in the present case suggested the diagnosis of an "intermediate" type of Chiari malformation, which could be considered a "severe" type I. Loss of cerebellar substance, easily determined by CT, is not generally considered a manifestation of Chiari malformation. A bony posterior fossa of small capacity filled with brainstem and cerebellar substance is usually described [4-6].

Diffuse cerebellar ischemia from chronic compression would provide a speculative etiology for our patient's loss of cerebellar substance. No computed tomographic evidence for acute or subacute ischemic brain injury (that is, leukoencephalopathy, pathologic contrast medium enhancement, mass effect) was noted. No arterial occlusions were noted to the limits of subtraction angiography. These findings are not surprising, as the ischemic injury would be expected to arise from previous chronic compression of small vessels. This mech-

Figure 2. Myelography with iophendylate (Pantopaque) enhancement. demonstrating caudal displacement of cerebellar tonsils to level of $C-2$ (arrows).

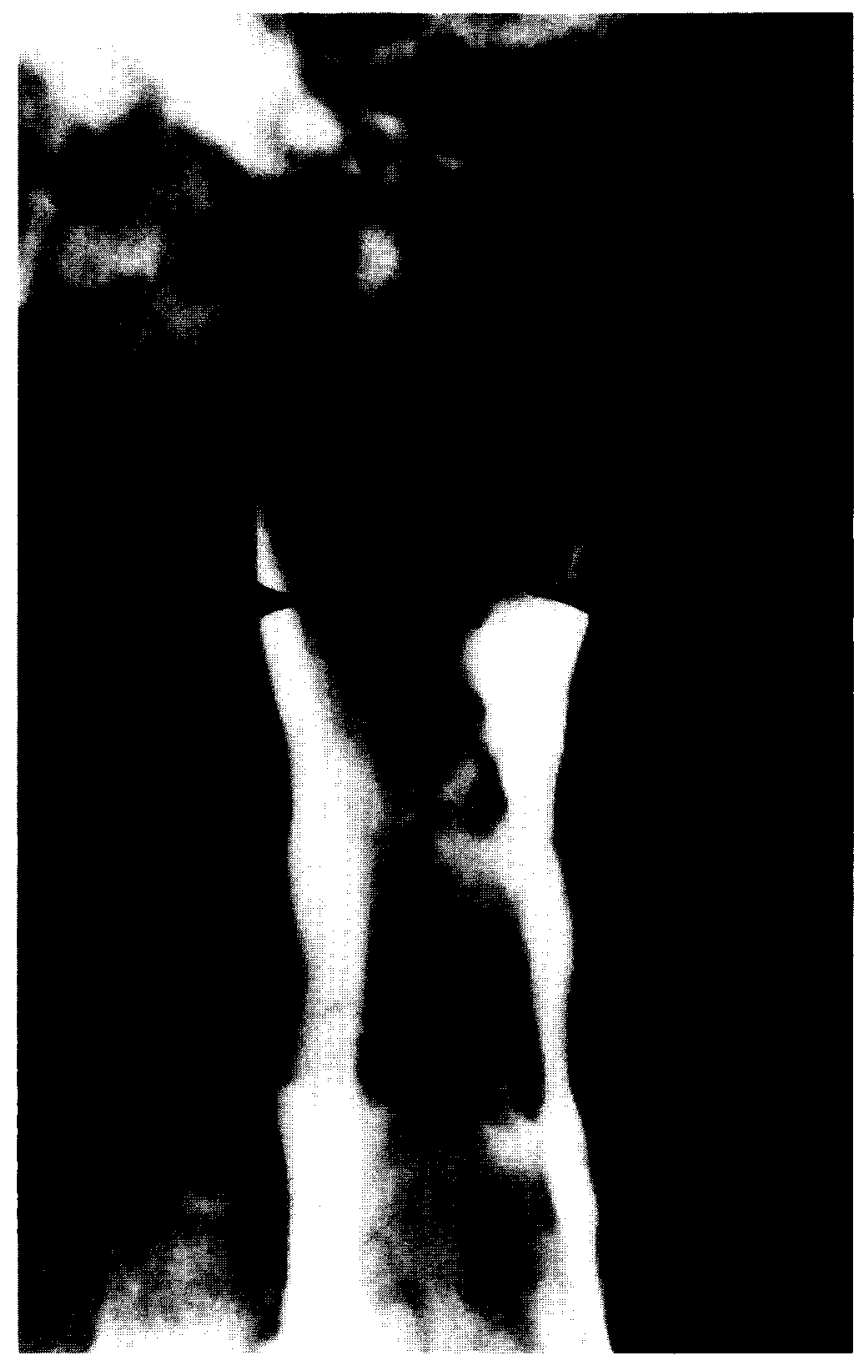




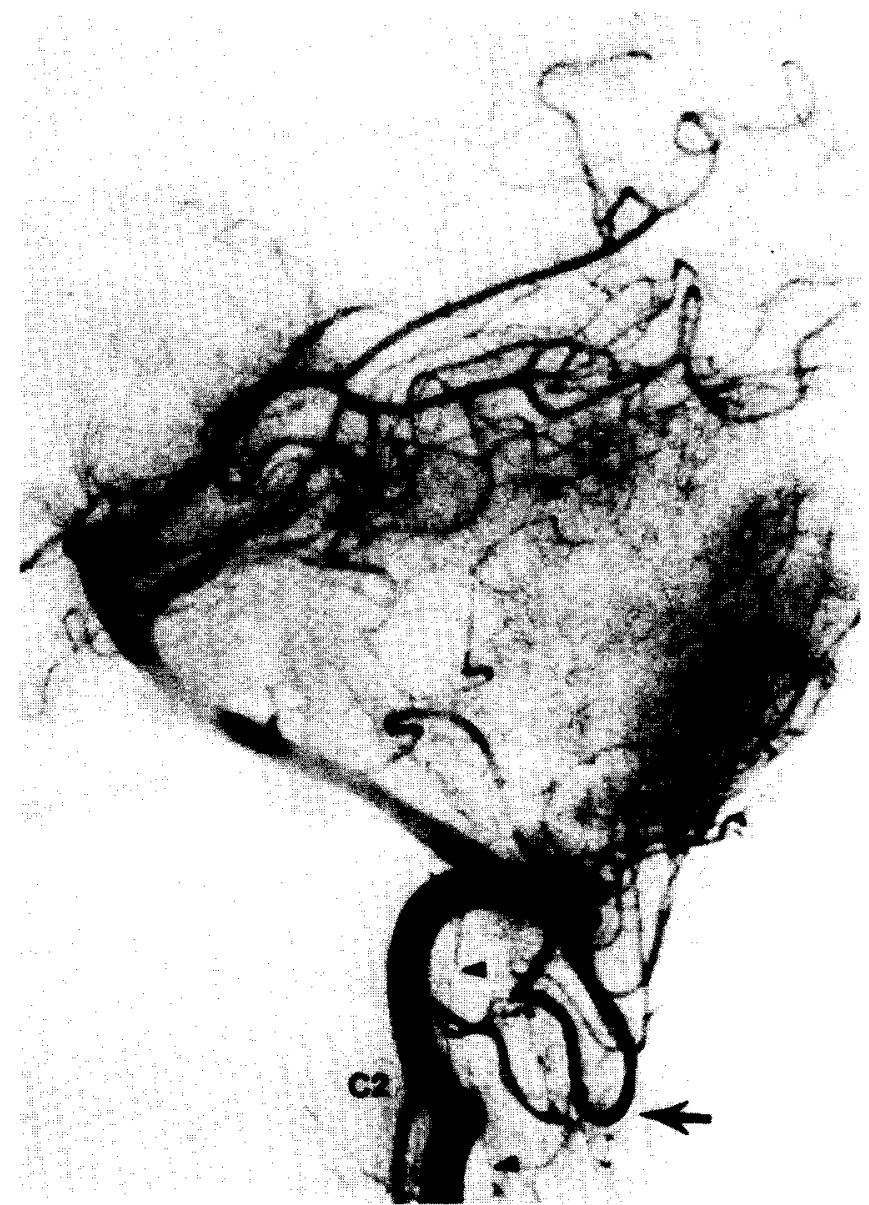

Figure 3. Subtraction film of vertebral angiogram, lateral view demonstrating caudal displacement of tonsillohemispheric branches and cranial loops of posterior inferior cerebellar artery and anterior inferior cerebellar-posterior inferior cerebellar arterial systems (arrow). These findings verify caudal displacement of the cerebellar tonsils and fourth ventricle. Delineation of the ventral cervical spinal cord (arrowbeads) is excellent.

anism would also explain the apparent sparing of deep cerebellar and brainstem substance.

Clinical presentations of mild degrees of Chiari malformation are usually confusing $[1,7,8]$. Only by meticulous neurological testing was downbeat nystagmus, a significant finding suggestive of Chiari malformation [1,2], appreciated. This discovery led to a definitive diagnosis and therapy. This patient previously carried a relatively hopeless diagnosis of olivopontocerebellar degeneration. Computed tomographic cisternography with metrizamide enhancement could have been used in place of clivomyelography. Chiari malformation should be included in the differential diagnosis by $\mathrm{CT}$ scanning of loss of cerebellar substance to increase both clinical and neuroradiologic vigilance regarding this potentially treatable disease. At least, loss of cerebellar substance should not be considered as evidence to exclude Chiari malformation.

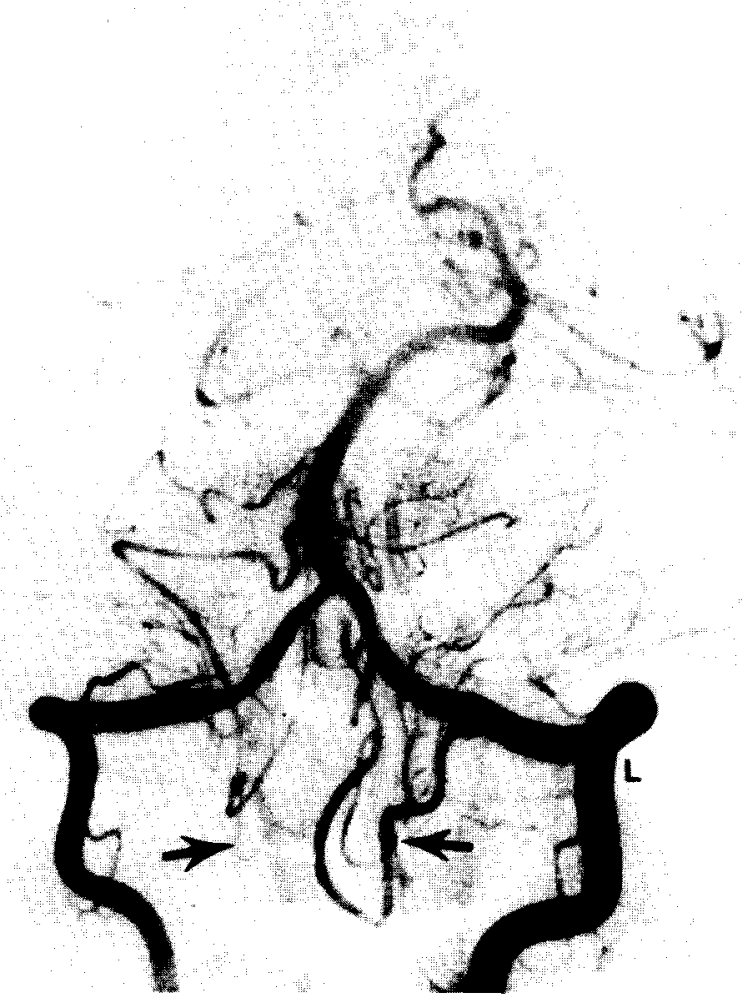

Figure 4. Subtraction film of transfacial vertebral angiogram, anteroposterior view, again showing caudal displacement of tonsillohemispheric branches (arrow's). The configuration of the right anterior inferior cerebellar-posterior inferior cerebellar arterial systems is a normal variant.

The authors with to express their appreciation to Ms. Sandra Ressler for her secretarial assistance.

\section{References}

1. Baloh RW, Spoonet JW. Downbeat nystagmus: a type of central vestibular nystagmus. Neurology (Minneap) 1981;31:304-10.

2. Cogan DG. Downbeat nystagmus. Arch Ophthalmol 1968;80:757-68.

3. Gabrielsen TO, Seeger JF, Amundsen P. Some new angiographic observations in patients with Chiari Type I and II malformations. Radiology 1975;115:627-34.

4. Naidich TP, Pudlowski RM, Naidich JB. Computed tomographic signs of the Chiari II malformation, part II: midbrain and cerebellum. Radiology 1980;134:391-8.

5. Naidich TP, Pudlowski RM, Naidich JB. Computed tomographic signs of the Chiari II malformation, part III: ventricles and cisterns. Radiology 1980;134:657-63

6. Naidich TP, Pudlowski RM, Naidich JB, Gornish M, Rodriguez FJ. Computed tomographic signs of the Chiari II malformation, part I: skull and dural partitions. Radiology $1980 ; 134: 65-71$.

7. Saez RJ, Onofrio BM, Yanagihara T. Experience with Arnold-Chiari malformation, 1960 to 1970 . J Neurosurg 1976;45:416-22.

8. Wilkins RH, Brody IA. The Arnold-Chiari malformations. Arch Neurol 1971;25:376-9. 